\title{
NEIBA
}

\section{A POLITICA EXTERNA DE MAURÍCIO MACRI: ESTUDO DE CASO SOBRE O PAPEL ARGENTINO NA CRISE DA VENEZUELA}

\author{
Beatriz Bandeira de Mello
}

Vínculo Institucional: Graduada em Ciência Política pela Universidade Federal do Estado do Rio de Janeiro (UNIRIO) e Mestranda do Programa de Pós-Graduação em Ciência Política da UNIRIO. Assistente de Pesquisa no Grupo de Relações Internacionais e Sul Global (GRISUL/UNIRIO) e no Laboratório de Estudos de Mídia e Esfera Pública (LEMEP/UERJ) ${ }^{1}$

\section{Resumo:}

O presente artigo analisa a política externa do presidente Maurício Macri eleito em dezembro de 2015. O objetivo é identificar características do atual modelo de inserção internacional argentino frente aos desafios regionais a partir do contraste com a posição defendida nos anos Kirchner. O trabalho parte de um estudo de caso sobre o papel da diplomacia argentina na escalada da crise na Venezuela. A metodologia empregue tem como base a análise crítica dos discursos oficiais do presidente Maurício Macri e dos chanceleres que compõem o Ministerio de Relaciones Exteriores y Culto e também dos comunicados e notas emitidos no período entre dezembro de 2015 e dezembro de 2017. Sugere-se que a postura assumida pela diplomacia argentina e, em particular, pelo presidente Maurício Macri, representa uma mudança em relação ao governo anterior principalmente no que tange à pauta de integração regional e ao alinhamento com os países da América Latina.

Palavras-chaves:

Política Externa; Argentina; Venezuela

Abstract:

\footnotetext{
${ }^{1}$ Recebido em: 12 de Dezembro de 2018 // Received on: December 12, 2018 Aceito em: 7 de Abril de 2019 // Accepted on: April 7, 2019
} 


\section{NEIBA}

\section{8}

This article analyzes the foreign policy of president Maurício Macri elected in december of 2015. The objective is to identify characteristics of the current model of argentine international insertion in face of the regional challenges, starting from the contrast with the position defended in the Kirchner's years. The paper starts from a case study on the role of argentine diplomacy in the escalation of the crisis in Venezuela. The methodology used is critical discourse analysis based in official speeches of president Maurício Macri and the Foreign Ministers of the Ministerio de Relaciones Exteriores y Culto, as well as the communiqués and notes issued between december 2015 and december 2017. It is suggested that the position taken by argentine diplomacy and, in particular, by president Maurício Macri, represents a change from the previous government, mainly in relation to the pattern of regional integration and alignment with the countries of Latin America.

\section{Keywords:}

Foreign Policy; Argentina; Venezuela 


\section{NEİBA}

\section{Introdução}

A eleição de Maurício Macri em 2015 compõe um novo quadro da conjuntura política, econômica e social na América Latina. O presidente eleito, integrante da coligação política Cambiemos ${ }^{2}$, venceu com $51,34 \%$ dos votos no segundo turno disputado com o candidato do kirchnerismo Daniel Scioli. A vitória de Macri é significativa já que interrompe 12 anos de mandatos kirchneristas na Argentina. Tal fato indica uma alteração na configuração dos governos latinoamericanos atuais em contraste com o perfil da Maré Rosa iniciada nos anos 2000 (PANIZZA, 2006).

Maurício Macri é ligado a um dos grupos empresariais mais importantes da Argentina. Foi presidente do clube de futebol Boca Juniors por três vezes consecutivas (1995-1999-2003), começando sua trajetória política ainda em 2003 como um dos criadores do movimento político Compromiso para el Cambio - que mais tarde se converteria no partido Propuesta Republicana (PRO). Antes de ser presidente foi Deputado Nacional em 2005; em 2007 e 2011, exerceu o cargo de prefeito de Buenos Aires ${ }^{3}$. Depois, já pelo PRO, concorreu nas eleições presidenciais com um discurso de "mudança" e "renovação".

Durante a campanha, a coligação Cambiemos se empenhou na diferenciação em relação ao kirchnerismo (PEREIRA, 2016). Nesse sentido, a plataforma política apresentada pela coligação concentrou-se em três objetivos principais: unir os argentinos, combater o narcotráfico e atingir o nível de pobreza zero. Para alcançar essas metas, Macri confiou à diplomacia a tarefa de impulsionar uma política externa de abertura ao mundo, com uma visão integradora, capaz de conferir ao país maior protagonismo

\footnotetext{
${ }^{2}$ Coligação formada em 2015 pelos partidos Coalición Cívica ARI, Propuesta Republicana (PRO) e Unión Cívica Radical para disputa das eleições presidenciais no mesmo ano.

3 Casa Rosada. Biografia do Presidente Maurício Macri. Disponível em < https://www.casarosada.gob.ar/el-presidente/biografia> Acesso em 20 de junho de 2018.
}

em nível regional e global (ARGENTINA, 2016). Portanto, a principal preocupação do governo passou a ser então a "reinserção" da Argentina no cenário internacional.

A escolha de Susana Malcorra para o Ministerio das Relaciones Exteriores y Culto (MREYC) revela certo pragmatismo da gestão Macri. A diplomata foi chefe de gabinete do Secretário-Geral das Nações Unidas, Ban Ki Moon e tem longa trajetória dentro da ONU. Ao assumir o MREYC, Malcorra declarou que sua intenção era "desideologizar" a política externa argentina (CARLIN, 2016). Seu sucessor, Jorge Faurie, também é diplomata de carreira e antes de assumir o Ministério foi Embaixador na França. A trajetória de Faurie nas relações exteriores começou em 1975. Desde então atuou na Embaixada da Venezuela, do Brasil e de Portugal.

Com um corpo diplomático técnico e uma estratégia voltada para a diversificação de parceiros internacionais, as expectativas sobre o governo Macri aumentaram. A perspectiva de mudanças na condução das políticas interna e externa, em oposição ao estilo de governo kirchnerista foram suficientes para angariar apoio ao governo de Macri. Nos seis primeiros meses de mandato o presidente argentino recebeu a visita do presidente dos Estados Unidos, Barack Obama, do presidente francês François Hollande e do primeiro-ministro italiano, Mateo Renzi. Ao comunicar a visita do presidente Barack Obama a chanceler Susana Malcorra declarou:

"A visita de Barack Obama é outra prova convincente do que estamos dizendo: a Argentina está se reinserindo no mundo, mantendo e abrindo vínculos com todos os nossos interlocutores e potenciais parceiros." (MALCORRA, 2016 - grifo e tradução da autora)

A princípio, a reorientação da política externa argentina sob Macri se concentrou em três pontos principais: as modificações no programa econômico-comercial em direção a um paradigma liberalizante, voltado para absorção 


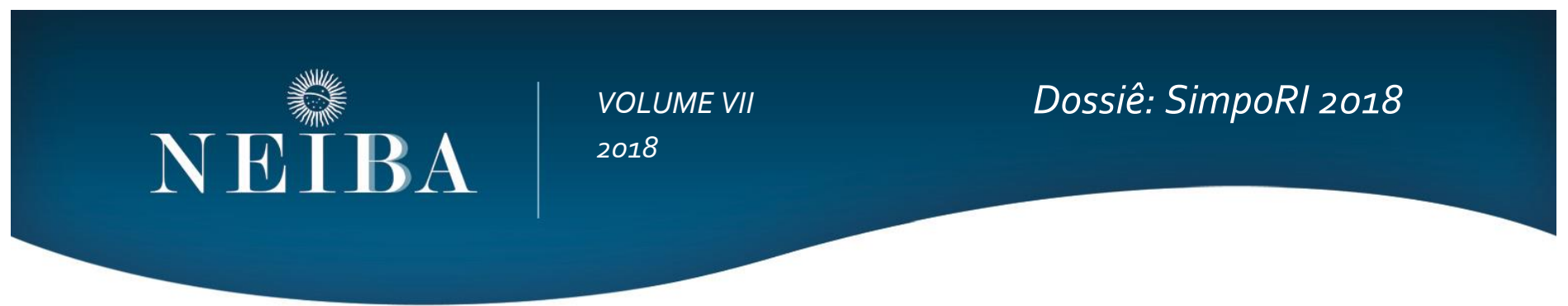

de investimentos estrangeiros e recuperação da confiança e credibilidade internacionais; o afastamento do "eixo bolivariano", e o consequente isolamento da Venezuela; e a reaproximação com países considerados "tradicionais", como França, Espanha e Estados Unidos (PEREIRA, 2016).

A crise venezuelana foi um dos primeiros desafios enfrentados pela diplomacia argentina, visto que a relação entre os dois países modificou-se rapidamente em comparação ao governo anterior. Com Néstor e Cristina Kirchner a América do Sul foi prioridade. Brasil, Venezuela, Bolívia e, em menor escala, Cuba, se tornaram parceiros estratégicos tanto em nível internacional, principalmente nas negociações comerciais no âmbito da OMC e na ONU, quanto em nível regional - dentro do MERCOSUL e da UNASUL. Entre 2003 e 2014, as relações com a Venezuela foram marcadas por uma forte aproximação devido ao apoio político e financeiro dado pelo governo venezuelano ao processo de recuperação da economia argentina pós-crise de 2001.

Ao longo dos governos Kirchner a Argentina se tornou um dos principais países apoiadores da entrada da Venezuela no Mercosul. Com a promulgação do Protocolo de Caracas, que consolidou o ingresso venezuelano no bloco, o governo argentino manifestou-se rapidamente a favor da decisão. O apoio argentino à entrada e permanência da Venezuela no Mercosul foi pautado pela vontade de conferir maior equilíbrio ao bloco em oposição ao peso do Brasil no plano de integração regional (RUIZ, 2010)

A aproximação entre os presidentes Néstor Kirchner e Hugo Chávez foi consolidada em julho de 2006 quando ambos firmaram um Acordo para o Estabelecimento de uma aliança estratégica entre a Argentina e a Venezuela (RUIZ, 2010). O ato solidificou a parceria iniciada em 2003 e a partir de então o apoio recíproco deu o tom das relações diplomáticas entre os dois governos. O diálogo entre Argentina e Venezuela se fez possível graças ao pragmatismo dos presidentes Kirchner e Chávez baseado, sobretudo, no interesse mútuo de fortalecimento da projeção internacional - possibilitando o aumento da margem de manobra econômica, comercial e política. Importante para a resolução de problemas internos, principalmente econômicos, a relação Argentina-Venezuela contribuiu também para a diversificação de parceiros diminuindo, por exemplo, a influência brasileira na política externa argentina.

A vitória eleitoral de Nicolás Maduro em 2013, contudo, transformou drasticamente a política e a economia venezuelanas. Com o falecimento de Hugo Chávez as críticas de setores internos da política argentina ao estilo de governo venezuelano se acirraram contra o modelo considerado autoritário e anti-capitalista do regime chavista. $\mathrm{Na}$ Venezuela, o conflito se intensificou ainda em 2013 quando a oposição decidiu não reconhecer o resultado das eleições. Nesse momento, Cristina Fernández manteve-se ao lado da Venezuela, defendendo a soberania, a autonomia e os processos internos do país, denunciando, inclusive, a atuação da oposição venezuelana como anti-democrática.

Ao assumir a presidência argentina em 2015 Macri teve que lidar com a escalada da crise no país vizinho em meio a manifestações e declarações públicas realizadas tanto pelo governo Maduro quanto por opositores. Mesmo antes de assumir a presidência, Macri já esboçava as linhas de sua ação internacional sugerindo uma mudança no posicionamento argentino em relação à Venezuela. Os primeiros indícios foram confirmados durante sua participação na $49^{\circ}$ Cúpula dos Chefes de Estado do Mercosul.

Destarte, considerando a eleição de Maurício Macri em 2015 e o cenário político na Venezuela, o presente trabalho tem como objetivo principal analisar o papel da diplomacia argentina na escalada da crise venezuelana que terminou com a suspensão do país do Mercosul em agosto de 2017. 


\section{NEIBA}

Para alcançar esse objetivo analisarei os discursos do presidente Maurício Macri, os pronunciamentos da chanceler Susana Malcorra e de seu sucessor Jorge Faurie e os comunicados oficiais emitidos pelo Ministerio de Relaciones Exteriores y Culto entre 2016 e 2017. Para empreender esta análise o presente trabalho se divide em quatro seções. A presente Introdução, seguida por um breve apontamento sobre a Análise Crítica do Discurso; a apresentação dos dados e por fim as conclusões.

\section{A análise crítica do discurso}

O uso da análise de discurso em pesquisa qualitativa é frequente nas Ciências Sociais. No entanto, sua aplicabilidade enquanto instrumento de análise provoca inúmeros questionamentos e debates devido a diversidade de significados atribuídos ao termo "discurso". Para os analistas críticos, como Nornan Fairclough e Teun Van Dijk, o discurso é um "evento comunicativo" que engloba - além das modalidades escrita e falada - a expressão corporal, as imagens, a diagramação, a entonação da voz e a materialização de ideologias (FAIRCLOUGH, 2001; MELO, 2009; VAN DIJK et al. 2013). Para estes autores o discurso é também "uma prática social reprodutora e transformadora de realidades sociais" (FAIRCLOUGH, 2001 apud MELO, 2009)

A Análise Crítica do Discurso (doravante ACD) não é simplesmente um método, mas uma disciplina transversal com várias subdisciplinas e áreas (VAN DIJK et al., 2013). É uma forma de investigação que dialoga com as mais variadas ordens sociais e que busca "esclarecer como os discursos estão conectados com as estruturas sociopolíticas mais abrangentes de poder e dominação" (KRESS, 1990 apud MELO, 2009). Os analistas críticos do discurso oferecem uma perspectiva crítica de produção de conhecimento focada nos problemas sociais e preocupada com o papel do discurso na produção e reprodução da desigualdade social (VAN DIJK, 1993).
A ACD se concentra nas estruturas discursivas que "legitimam o controle, ou de outra forma, naturalizam a ordem social e, especificamente, as relações de desigualdade" (VAN DIJK, 1993). A leitura dos elementos intrínsecos a estrutura discursiva são fundamentais na análise crítica. No entanto, estes elementos são imperceptíveis sem a compreensão do contexto, das características de quem fala, dos objetivos pretendidos e da ideologia dominante.

O presente trabalho se baseia em quatro categorias analíticas ${ }^{4}$ apontadas por Van Dijk, a saber: os tópicos, a representação dos grupos, implícitos e contexto. Os tópicos têm um papel fundamental na interação entre agentes e na comunicação (VAN DIJK et al. 2013). Através deles é possível inferir o que o discurso "quer dizer" em temas gerais. Uma análise crítica dos tópicos do discurso permite identificar os temas preferencialmente abordados pelo falante e como eles se conectam com a representação dos grupos, com a ideologia e com o propósito do texto (VAN DIJK, 1993)

A representação dos grupos é um dos elementos centrais da ACD. Os discursos geralmente se apóiam em uma estratégia de representação positiva do próprio grupo (endogrupo) e uma representação negativa do outro (exogrupo) (VAN DIJK, 1993). Nesse sentido, as características positivas do próprio grupo e os elementos negativos do outro grupo são enfatizados, enquanto as características negativas do endogrupo e os pontos positivos do exogrupo são minimizados. A escolha de palavras, os exemplos, e os fatos que dão suporte ao discurso podem enfatizar o contraste entre os grupos sugerindo uma polarização. A diferenciação é importante na construção de modelos mentais e atitudes sobre os grupos em questão.

Os significados implícitos, como sugerem, não estão explícitos na fala (ou texto), mas permitem interpretações

\footnotetext{
4 Os instrumentos de análise selecionados são compatíveis com os objetivos deste trabalho. Para consultar outras ferramentas da Análise Crítica do
} Discurso ver Van Dijk (1993). 


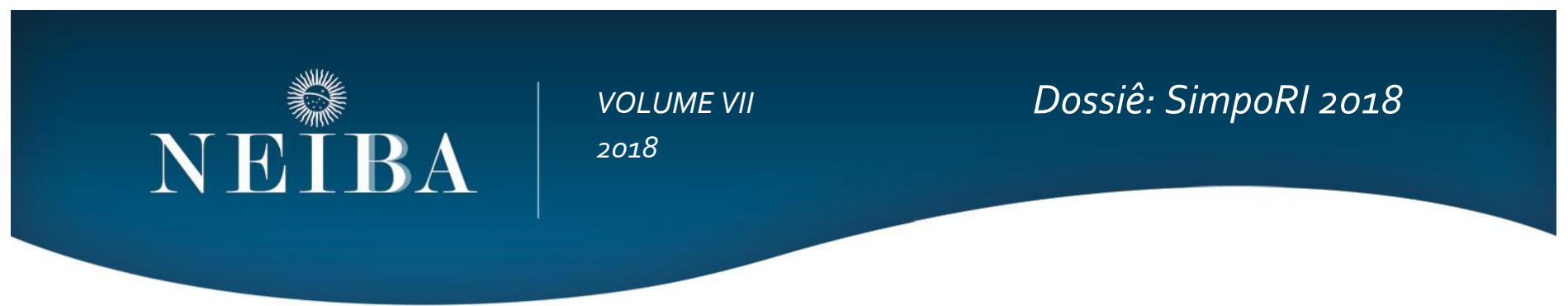

sobre as informações apresentadas. Coelho e Santos (2014) em referência ao trabalho de Flores (2007), destacam que os significados implícitos são um recurso utilizado quando o emissor deseja transmitir uma informação, mas o faz de forma inacabada, esperando que o receptor complete o resto a partir do conhecimento que tem sobre os fatos apresentados - a partir de crenças fundamentais, geralmente ideológicas (VAN DIJK et al.2013; COELHO \& SANTOS, 2014).

Os objetivos da análise crítica só podem ser alcançados "quando as estruturas discursivas estiverem relacionadas com as estruturas globais e locais do contexto" (VAN DIJK et al. 2013). O contexto global compreende as estruturas históricas, políticas, culturais e sociais associadas a um discurso. O contexto local diz respeito a situação imediata que o discurso acontece. Ele envolve, basicamente, os participantes e seus conhecimentos, bem como as normas e o local do discurso. Os elementos contextuais, portanto, "são limitadores das propriedades do texto e da conversação, ou seja, o que dizemos e como dizemos depende de com quem estamos falando, quando, onde e do nosso propósito" (VAN DIJK et al. 2013).

Com base nos recursos definidos por Van Dijk propomos uma análise crítica de alguns trechos de pronunciamentos realizados pelo presidente argentino Maurício Macri e pelos ministros titulares do Ministerio de Relaciones Exteriores y Culto entre 2016 e 2017 bem como dos textos produzidos pelo Ministerio (como notas à imprensa e comunicados oficiais). Os documentos servem como aporte contextual para os discursos analisados. A relevância do presidente para esta análise recai sobre o conceito de diplomacia presidencial 5 .

\footnotetext{
${ }^{5}$ Entende-se como diplomacia presidencial a diplomacia exercida diretamente por chefes de estado. Para Preto (2006 p.31), a diplomacia presidencial "é o nome que assume a 'diplomacia de cúpula' em regimes presidencialistas, sendo a diplomacia de cúpula a condução pessoal (do chefe de estado) de assuntos de política externa". Outra definição aceita é a
}

Os documentos e discursos indicam traços da estratégia de inserção internacional adotada pelo governo argentino, pois transmitem, legitimam e justificam, no marco institucional, a posição assumida pelo país nos episódios analisados nesse trabalho. O critério adotado para a seleção da amostra foi a citação direta à crise na Venezuela ou ao governo/oposição venezuelano. Todos os discursos de chanceleres e documentos foram retirados do portal oficial do Ministério de Relaciones Exteriores y Culto (MREYC), à exceção dos pronunciamentos do presidente Macri obtidos através do endereço eletrônico da Casa Rosada - sede do governo nacional.

$\mathrm{Na}$ próxima seção tratamos dos principais elementos do discurso argentino em relação à Venezuela, as principais características da política externa argentina de Macri observadas que dialogam com o caso venezuelano e o posicionamento adotado em relação à crise a partir de um contraste com a postura assumida pelo país ao longo dos governos Kirchner.

\section{Elementos do discurso argentino}

Para entender o posicionamento argentino frente à crise venezuelana durante o governo Macri precisamos voltar ao final de 2015, momento onde as primeiras declarações sobre a situação da Venezuela foram feitas pelo presidente. Durante a campanha presidencial, Macri já se mostrava favorável à aplicação da cláusula democrática do Mercosul para suspensão da Venezuela. Em eventos públicos chegou a questionar abertamente a permanência do país no bloco ${ }^{6}$. No entanto, foi durante a $49^{\circ}$ Cúpula dos Chefes de Estado

de Albuquerque que define a diplomacia conceitual como "a participação pessoal do chefe de governo/estado nas relações internacionais, seja por meio de pronunciamentos, seja pela participação em foros internacionais, seja atuando diretamente em negociações (HORTA, 2012)

${ }^{6}$ Argentina e Venezuela trocam acusações em cúpula do Mercosul.

Disponivel em < https://www.terra.com.br/noticias/argentina-e-venezuelatrocam-acusacoes-em-cupula-do-

mercosul,54142a972973adog3f67db681e4b1d2eqcuxluv4.html> Acesso em 20 de junho de 2018. 


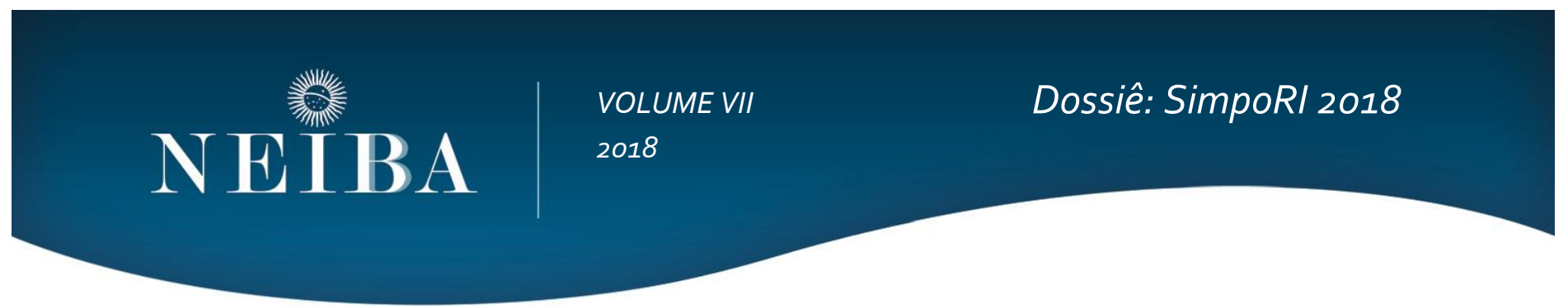

do Mercosul, realizada em dezembro de 2015, que a posição argentina em relação à Venezuela ganhou destaque.

No seu primeiro evento internacional, Macri protagonizou um embate com a chanceler venezuelana Delcy Rodríguez - que substituiu o presidente Nicolás Maduro. Na ocasião, Macri e Rodríguez apresentaram visões distintas sobre manifestações e direitos humanos. O pedido feito por Macri para liberação de presos políticos foi visto como "ingerência nos assuntos internos da Venezuela". Rodríguez também destacou o que considerou uma "dupla moral" de Macri na questão de direitos humanos, citando o processo de Hebe de Bonafini, uma das líderes do movimento das Mães da Praça de Maio. Ao confrontar Macri, Delcy Rodríguez apresentou fotos dos protestos em Caracas, em 2014, chamando atenção para atos de violência. Depois acusou o presidente argentino de defender Leopoldo López, organizador dos protestos e um dos principais líderes da oposição ao governo Maduro.

Ao discursar contra as prisões o presidente argentino defendeu a prevalência de uma "cultura democrática" no bloco, argumentando que no Mercosul não há espaço "para perseguição política por razões ideológicas". Nesse ponto, ao reivindicar uma democracia pautada na inclusão e na participação, o presidente deixa implícito o contraste entre a proposta argentina de integração regional e a situação de crise política da Venezuela que não estaria de acordo com os princípios adotados pelo Mercosul. A posição indica um traço característico do discurso argentino: a diferenciação entre um país que respeita a democracia (governo argentino - endogrupo) e outro que não respeita (governo venezuelano - exogrupo).

"(...)gostaria de pedir aos Estados Partes, e especialmente ao governo venezuelano, que trabalhem incansavelmente para consolidar uma verdadeira cultura democrática em nossa região, uma democracia, isso inclui todos. É nesse sentido que quero perguntar expressamente aqui diante de todos os queridos presidentes dos Estados Partes $e$ associados do Mercosul, pela pronta libertação dos presos políticos na Venezuela. Porque nos países membros do Mercosul não pode haver lugar para a perseguição política por razões ideológicas ou a privação ilegítima da liberdade de pensar diferentemente." (MACRI, 2015 - tradução e grifos da autora)

A definição de democracia mobilizada pelo presidente é o cerne de toda a atuação diplomática argentina nos episódios que remontam à crise venezuelana. Em um dos trechos de sua fala Macri deixa clara sua posição:

"Minha visão de democracia vai muito além de ir às urnas a cada certo período de tempo, a democracia é um modo de vida, um pacto de convivência entre pessoas que pensam de maneira diferente, é uma maneira de cuidar das pessoas e de processar dissensões para melhorar as coisas, porque essa é a diversidade na qual nos enriquecemos. Acho que chegou a hora, queridos amigos, de pedir um pouco mais de democracia. No século $X X$, nós superamos as ditaduras e nunca mais voltamos a dizer aos governos militares, agora o século 21 exige mais audácia e compromisso com uma nova democracia, mais participativa, mais inclusiva" (MACRI, 2015 tradução e grifos da autora)

A opção por uma "democracia mais participativa e inclusiva", com "pessoas que pensam distinto" deixa implícita no discurso do argentino uma aproximação com a oposição venezuelana. Macri também se apropria de estruturas de contexto global ("séculos XX e 21") para contrastar um passado de "ditaduras" e "governos militares" a um presente de "democracia inclusiva" - com o elemento implícito que o governo venezuelano estaria na primeira categoria. 


\section{NEIBA}

Desde o referido episódio as relações ArgentinaVenezuela adquiriram um novo viés, com mais críticas argentinas ao governo de Nicolás Maduro e crescente simpatia pela oposição venezuelana. As declarações do presidente Maurício Macri, da chanceler Susana Malcorra e, em menor escala, de Jorge Faurie, bem como os comunicados do governo argentino sobre a crise venezuelana foram constantes e reativos aos acontecimentos do país. As pressões em instâncias multilaterais, como o Mercosul e a OEA, também aumentaram progressivamente, como veremos adiante.

O gráfico abaixo mostra o número de manifestações oficiais do governo7, entre discursos, declarações e comunicados oficiais que trataram diretamente da crise venezuelana. Entre posições favoráveis ao diálogo e críticas aos protestos violentos, o governo argentino manteve-se ativo sobre a situação política na Venezuela durante todo o período analisado.

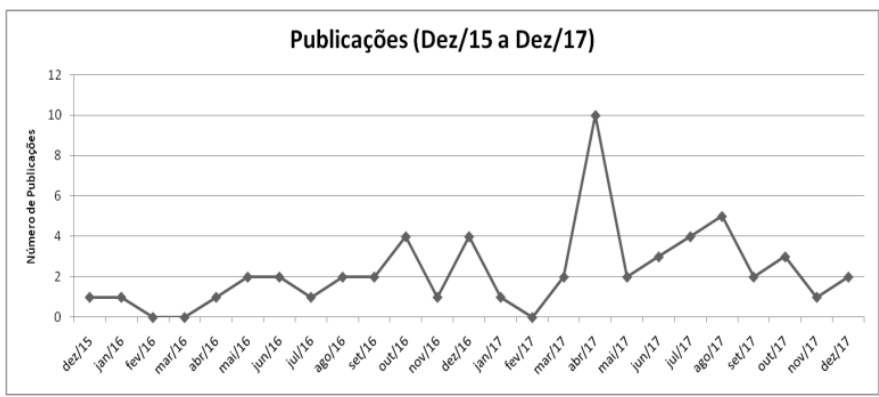

Fontes: Ministerio de Relaciones Exteriores y Culto;

Casa Rosada. Elaboração Própria (2018)

O propósito das recorrentes manifestações do governo em relação à Venezuela foi estabelecer e consolidar o posicionamento argentino como defensor dos direitos humanos e da democracia na região - postura que foi reforçada pelo presidente argentino ao longo de sua campanha presidencial e após sua posse. O discurso pautado

7 O número engloba as publicações coletadas no site do Ministerio de Relaciones Exteriores y Culto e da Casa Rosada entre janeiro de 2016 e dezembro de 2017. pela conciliação e diálogo conferiu protagonismo argentino no Cone Sul e proporcionou a aproximação do país com instâncias multilaterais criticadas pela ex-presidente Cristina Kirchner como, por exemplo, a Aliança do Pacífico.

No início de 2016, o governo argentino reconheceu de pronto o resultado das eleições legislativas para composição da Assembleia Nacional. O processo, supervisionado por uma Missão Eleitoral da UNASUL, garantiu maioria parlamentar à oposição. Um comunicado publicado em janeiro de 2016 apresenta a democracia como "vontade do povo". O episódio pressupõe o pleno funcionamento das instituições democráticas na Venezuela:

"(...) o governo argentino está convencido de que o respeito absoluto pela vontade do povo expressa livremente e democraticamente nas urnas, bem como a estrita observância dos privilégios, prerrogativas e garantias constitucionais, são condições inevitáveis para fortalecer as democracias na América Latina." (ARGENTINA, 2016 - tradução e grifo da autora)

Duas premissas do discurso argentino merecem destaque: a retomada da confiança e da credibilidade internacionais. Um apoio à oposição venezuelana e o apelo a realização de "eleições democráticas no país" reforçam essas premissas. O governo argentino, na figura de seu presidente e chanceleres, busca apoio nos eixos do poder econômico, principalmente os EUA para legitimar sua posição. Os ideais de "reinserção internacional" e "abertura econômica" (expressões frequentemente utilizadas pelo presidente argentino e por sua equipe diplomática) evidenciam uma estratégia de aproximação com EUA e Europa. Portanto, para o governo argentino, ser um país contrário ao regime venezuelano é um dos elementos que compõem essa estratégia.

Em maio de 2016, Susana Malcorra participou de uma reunião extraordinária do Conselho Permanente da 


\section{NEİBA}

OEA (Organização dos Estados Americanos) convocada especialmente para discutir a crise venezuelana. Depois das acusações de ingerência em assuntos internos da Venezuela, a chancelaria passou a discursar em um tom mais modesto, mostrando "preocupação" com a situação do país. Os diplomatas reforçaram uma posição no estabelecimento do "diálogo" e da "conciliação" entre as forças opositoras e o governo Maduro. Em uma das suas declarações, Malcorra afirma que:

"Não temos uma intenção intervencionista, mas uma intenção de contribuir para elevar o espaço do diálogo. Não se pode substituir a vontade dos venezuelanos de encontrar suas próprias soluções. Estamos esperando para acompanhar de nossa própria memória o que nos aconteceu em 2001, que é muito recente e que está no DNA de nossa sociedade" (MALCORRA, 2016 (A) tradução da autora)

O trecho mostra uma aparente simpatia com o povo venezuelano, que visa minimizar o impacto intervencionista das ações argentinas. Entretanto, por mais que tenha adotado uma postura conciliatória, o governo argentino não deixou de pautar a aplicação da clausula democrática como instrumento para isolar a Venezuela de fóruns multilaterais. As primeiras manifestações oficiais sobre o dispositivo emitidas pela chanceler Susana Malcorra, surgiram durante uma reunião especial dos chanceleres do Mercosul convocada pelo Paraguai - com forte apoio da Argentina. Durante a reunião, Malcorra deu indícios da possibilidade de aplicação do Protocolo de Ushuaia, dado o cenário de agravamento da crise venezuelana. Porém, a diplomacia argentina assumiu uma postura colaboracionista e participativa, reforçando o diálogo. Os indícios apontam para uma estratégia do país na busca por uma posição de destaque na mediação de conflitos regionais.

"Quando nos reunimos (representantes de países do Mercosul) vamos falar como sempre com base em objetivos, dados e tentando colaborar. Se do que emerge houver mérito para a aplicação de elementos da cláusula democrática, o faremos, mas já dissemos muitas vezes que o único caminho para a Venezuela é o diálogo entre as partes. Nós não vemos de outra maneira" (MALCORRA, 2016b - grifo e tradução da autora)

Nesse contexto, o governo argentino foi favorável a todas as iniciativas propostas por governos locais e instituições venezuelanas para mediação da crise, principalmente as que contavam com a participação da oposição - representada pela Mesa de União Democrática $(M U D)^{8}$. Dois exemplos são: a avaliação positiva do Conselho Nacional Eleitoral (CNE) venezuelano que validou as assinaturas para o referendo revogatório contra o governo Maduro e a mensagem que celebrou o início das tratativas entre o governo e os representantes da MUD. Em comunicado assinado pelos chanceleres da Argentina, Chile e Uruguai, a decisão do CNE foi vista como "um primeiro passo para a pacificação" (MREYC, 2016 - tradução e grifo da autora).

Entretanto, em setembro de 2016, Argentina, Brasil, Uruguai e Paraguai impediram a Venezuela de assumir a presidência temporária do Mercosul devido ao não cumprimento de acordos relacionados ao Protocolo de Adesão. Essa decisão aumentou o isolamento da Venezuela no bloco e somou pressões internacionais para aplicação da cláusula democrática. Na ocasião, os representantes dos países decidiram se reunir novamente em $1^{\circ}$ de dezembro para uma reavaliação da situação venezuelana. Susana Malcorra esteve em todas as reuniões de cúpula do Mercosul para discutir e apresentar soluções para a crise venezuelana o que mostra um grande interesse do país na questão.

Os tópicos que embasaram o impedimento no Mercosul foram comerciais e econômicos. A estrutura foi

\footnotetext{
${ }^{8}$ A Mesa de Unión Democrática é a coalizão de partidos venezuelanos de oposição ao governo de Nicolás Maduro.
} 


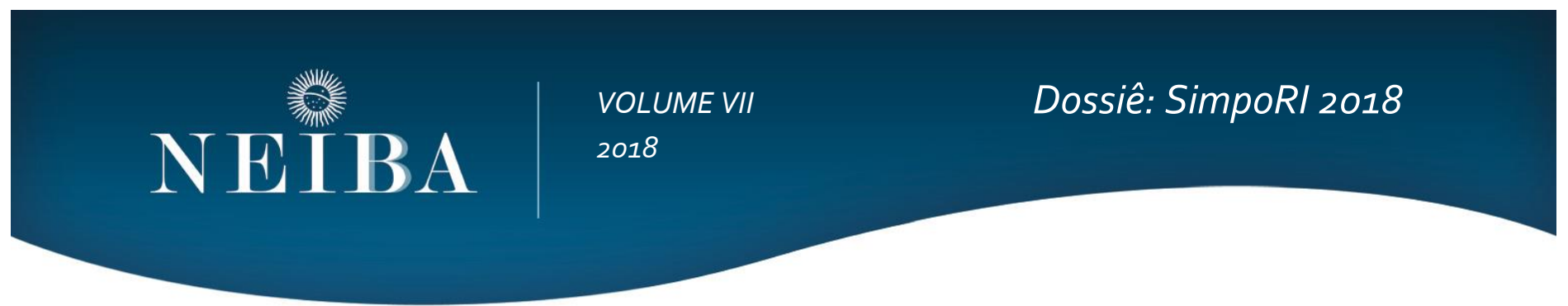

utilizada para indicar que decisão não teria nenhuma relação com a crise venezuelana. Implicitamente, a permanência venezuelana no bloco é apresentada como um entrave para o desenvolvimento de acordos em nível regional e global. Nas palavras de Malcorra, "o Mercosul é um ambiente de mercado, econômico, não é um ambiente político" (MALCORRA, 2016c - tradução da autora).

A diplomacia argentina teve forte participação na Organização dos Estados Americanos (OEA) ao longo de 2016. A Organização se colocou como uma alternativa aos fóruns regionais como o Mercosul e a UNASUL. Foi junto aos países da instituição que o governo argentino emitiu uma declaração, em outubro de 2016, contrária a decisão do Conselho Nacional Eleitoral (CNE) da Venezuela que postergou o referendo revocatório convocado pela oposição.

No mesmo período, a chanceler Susana Malcorra atuou em defesa da possível aplicação dos princípios da Carta Democrática da OEA. Porém, a formação de um consenso dentro da Organização para a aplicação de sanções à Venezuela foi dificultada pela divergência de opiniões sobre o caso. O estímulo venezuelano às associações caribenhas, notadamente ALBA e Petrocaribe, foi um fator que inibiu o avanço das proposições argentinas na entidade.

Alinhado a um posicionamento ativo na OEA, os chanceleres de Brasil, Uruguai, Paraguai e Argentina comunicaram à suspensão dos direitos da Venezuela no Mercosul em 02 de dezembro de 2016. No mesmo mês a chanceler venezuelana Delcy Rodríguez foi impedida de participar de reunião de cúpula realizada em Buenos Aires. $\mathrm{Na}$ ocasião Rodríguez acusou um "golpe" dentro da instituição". Em meio a discussões e pressões sobre a Venezuela, a Argentina assumiu a presidência temporária do

\footnotetext{
${ }^{9}$ El polémico intento de la canciller de Venezuela Delcy Rodríguez de entrar a la reunión de Mercosur. BBC Mundo. Disponível em < https://www.bbc.com/mundo/noticias-america-latina-38325056> Acesso em 2 de julho de 2018.
}

Mercosul, endurecendo o discurso em relação ao vizinho agora como liderança regional à frente do bloco.

A influência argentina dentro do Mercosul foi um instrumento que contribuiu para o isolamento político da Venezuela em nível regional. O conjunto de pressões externas, no Mercosul e na OEA, e críticas à política interna venezuelana estiveram presentes no discurso argentino. No episódio envolvendo uma decisão do Tribunal Supremo de Justicia (TSJ) venezuelano que limitou os poderes da Assembleia Nacional, o governo argentino manifestou, mais uma vez, sua preocupação com a crise política no país. $\mathrm{Na}$ ocasião, em comunicado emitido com os demais membros da UNASUL, o governo evocou os princípios da democracia liberal (separação de poderes, Estado de Direito, direitos humanos e instituições democráticas) ao defender o diálogo entre governo e oposição A declaração foi a única (no conjunto de documentos analisados neste trabalho) assinada pela UNASUL.

A estratégia da diplomacia argentina foi manter um discurso padronizado e consistente nas instituições com dispositivos democráticos (UNASUL, Mercosul e OEA). No âmbito regional, o debate sobre a aplicação efetiva da cláusula democrática do Mercosul tornou-se prioridade a partir de abril de 2017. Uma reunião realizada em Buenos Aires terminou com um compromisso firmado pelos países membros do bloco (Brasil, Argentina, Uruguai e Paraguai), levado à OEA pela chanceler Susana Malcorra. Durante uma Sessão Extraordinária do Conselho Permanente da Organização, Malcorra reafirmou o documento com as decisões tomadas em conjunto não representava um ato de ingerência.

"Este marco é o que indica claramente que a decisão que tomamos não interfere de forma alguma, a realidade é que o compromisso que assumimos ao assinar esses tratados impõe a todos os membros a obrigação de intervir conforme previsto por esses mesmos tratados quando algum dos seus Estados- 


\section{NEİBA}

Membros se desviar dos princípios estabelecidos." (MALCORRA, 2017A - tradução da autora)

A atuação argentina na Comunidade de Estados Latino-Americanos e Caribenhos (CELAC) foi moderada. O governo assinou um termo, em janeiro de 2017, reafirmando o apoio às tratativas de diálogo travadas entre o governo e a oposição, com a mediação de ex-presidentes e do Vaticano. A influência da Venezuela e o baixo interesse da diplomacia argentina na Comunidade não tornou propício uma atuação da diplomacia contrária ao governo venezuelano nesse ambiente.

A indicação de Jorge Faurie para o Ministerio de Relaciones Exteriores y Culto em virtude da saída de Susana Malcorra - que passou a integrar o Consejo de Alto Nível para el Análisis Global ${ }^{10}$ - manteve uma postura crítica e pragmática. Na OEA, em meados de 2017, Faurie apresentou a situação venezuelana como uma "crise humanitária" posição que se tornaria "oficial" posteriormente. Em junho, o governo argentino publicou uma nota conjunta expressando "decepção" com a falta de consenso regional na XXIX Reunião de Consulta de Ministros de Relações Exteriores da OEA sobre a situação venezuelana. Faurie criticou a Assembleia Constituinte convocada pelo presidente Nicolás Maduro e a violência empregue nas manifestações defendendo que esse tipo de ação não contribuiria com a resolução da crise venezuelana.

O desempenho de Faurie diante da crise na Venezuela foi moderado em relação à sua antecessora. Poucos foram os pronunciamentos feitos pelo chanceler que mencionaram a Venezuela. Ao que parece, Susana Malcorra tratou diretamente da questão cabendo a Faurie temas prioritariamente econômicos e comerciais, como a definição das tratativas para o estabelecimento do Acordo Mercosul-

\footnotetext{
${ }^{10}$ O Conselho seria um espaço de reflexão cuja finalidade é "a elaboração de aportes e recomendações sobre as principais tendências globais com uma perspectiva de longo prazo." (Cidade de Buenos Aires, Decreto 413/2017, 9 de junho de 2017). Susana Malcorra foi designada presidenta do Conselho.
}

União Europeia. No gráfico abaixo, vemos que Susana Malcorra teve um alto desempenho à frente da diplomacia argentina, ocupando a segunda posição na titularidade das publicações analisadas.

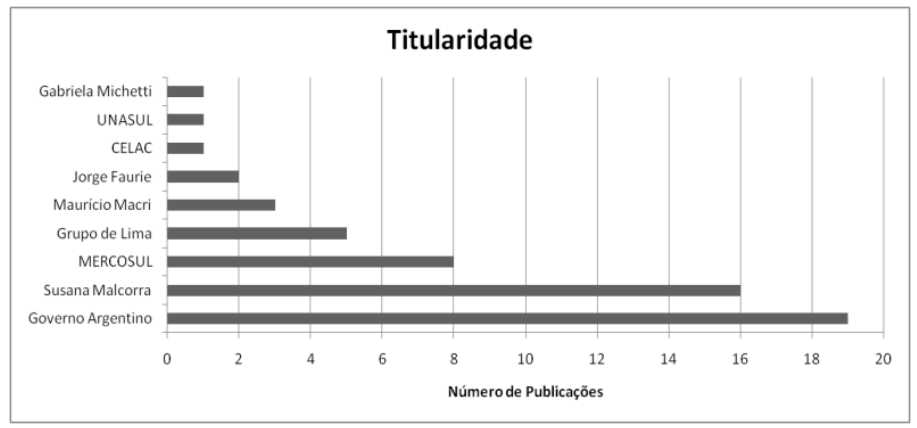

Fontes: Ministerio de Relaciones Exteriores y Culto e Casa Rosada. Elaboração própria (2018)

Nos momentos onde falou da crise venezuelana, Jorge Faurie fez críticas ao governo Maduro, manifestando apoio a instauração de um processo eleitoral e a restauração dos poderes facultados à Assembleia Nacional. Faurie também teve participação ativa na OEA - que se intensificou em 2018 - convocando os países da Organização a tomarem uma posição diante do agravamento da crise venezuelana. A atuação dentro da Organização foi uma das principais linhas de ação praticadas tanto por Susana Malcorra como por Jorge Faurie.

Os países membros do Mercosul decidiram suspender definitivamente a Venezuela do bloco em agosto de 2017. A atuação do Grupo de Lima, grupo criado exclusivamente para tratar da crise venezuelana composto por 12 países $^{11}$ foi o primeiro a apoiar a decisão do Mercosul. A Declaração de Lima, publicada três dias após a decisão da suspensão, indica posições e objetivos do Grupo de Lima em relação à Venezuela. Prevalece a denúncia da "ruptura da ordem democrática", o não reconhecimento da Assembleia

\footnotetext{
${ }^{11}$ Argentina, Brasil, Canadá, Chile, Colômbia, Costa Rica, Guatemala, Honduras, México, Panamá, Paraguai e Peru.
} 


\section{NEIBA}

Constituinte e o apoio à Assembleia Nacional, e a decisão de não apoiar qualquer candidatura venezuelana em mecanismos e organizações regionais e internacionais. O Grupo recebeu o apoio da União Europeia e da Organização dos Estados Americanos.

$\mathrm{Na} 72^{\mathrm{a}}$ Assembleia Geral das Nações Unidas a vicepresidente Gabriela Michetti reforçou a atuação do Grupo de Lima mostrando a "união" dos países engajados no grupo na condenação da ruptura da ordem democrática na Venezuela. A vice-presidente elencou aspectos procedimentais da democracia criticando a falta de eleições livres no país ponto que se tornou um dos pontos chave do discurso argentino a partir do segundo semestre de 2017.

"Senhor Presidente, com tristeza quero me referir à situação que a irmã República Bolivariana da Venezuela está passando. Em 8 de agosto, 12 Estados da América reunidos em Lima condenaram o colapso da ordem democrática e a violação sistemática dos direitos humanos e das liberdades fundamentais, a violência, a repressão, a perseguição política, a existência de presos políticos e a falta de eleições livres. É com dor que devo pronunciar hoje estas palavras sobre um país irmão. Eu faço desta tribuna, um chamado para fazer um esforço de negociação credivel e de boa fé, que tenha o consenso das partes e que seja orientado para alcançar pacificamente a restauração da democracia na Venezuela" (MICHETTI, 2017-tradução da autora)

Após a suspensão da Venezuela, as menções a crise venezuelana diminuíram significativamente. Os tópicos que ganharam destaque a partir de então foram: a aproximação com a Aliança do Pacífico e a conclusão do Acordo de Associação Mercosul-União Europeia. Na Cúpula do Mercosul, realizada em dezembro de 2017, Macri fala sobre um "Mercosul do Século XXI":
"Sem discutir seus objetivos estratégicos originais, precisamos de uma atualização do Mercosul, precisamos de um Mercosul para o século XXI. Precisamos que o nosso projeto de integração seja um instrumento de vanguarda, onde as decisões que tomamos levem em conta a dinâmica das mudanças regionais e globais." (MACRI, 2017- tradução da autora)

A nova postura em relação ao Mercosul engloba uma tendência observada ao longo dos discursos argentinos: a aproximação com países considerados "secundários" na política externa de Néstor e Cristina Kirchner. Durante os anos Kirchner, a Argentina fortaleceu os laços com Venezuela, Brasil, Bolívia e Cuba, deixando em segundo plano as relações com o México, Chile, Colômbia e Peru que se uniram para promover a Aliança do Pacífico. Podemos ver no gráfico abaixo indícios de uma aproximação argentina em direção ao Chile, Paraguai e Colômbia.

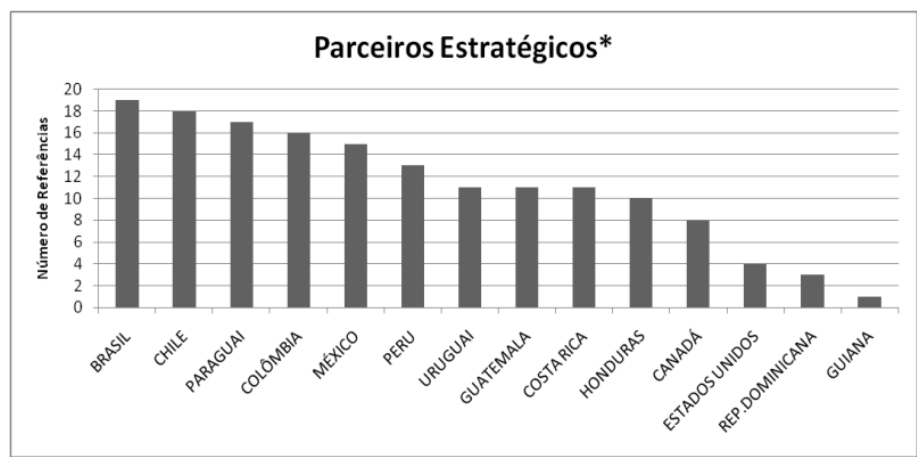

Fontes: Ministerio de Relaciones Exteriores y Culto e Casa Rosada. Elaboração própria (2018). *Declarações assinadas em fóruns ou cúpulas de organismos multilaterais (UNASUL, Mercosul, CELAC) não foram consideradas.

A alteração no padrão de integração regional tem relação direta com a proposta de política externa elaborada pelo presidente Maurício Macri e com as mudanças no contexto político regional. O discurso é favorável a uma aproximação com a Aliança do Pacífico, sem abandonar, 


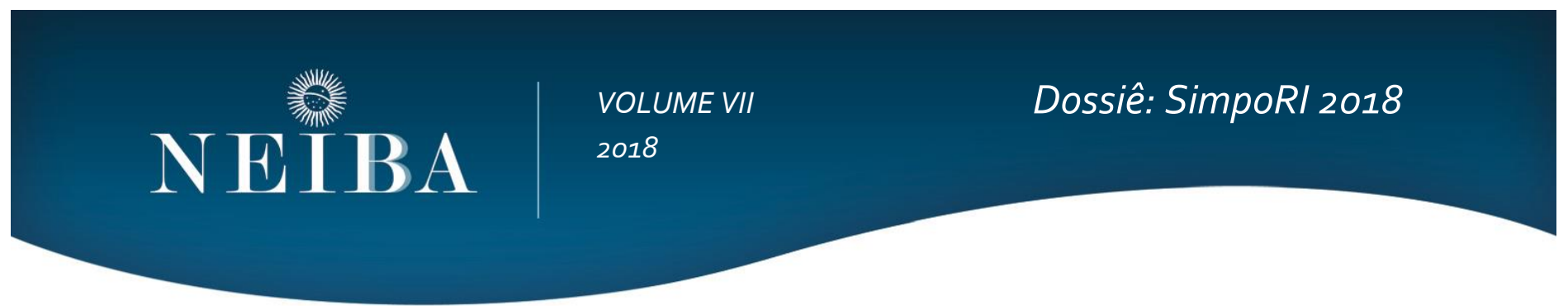

contudo o papel estratégico do Mercosul para a política comercial argentina. Isso explica, portanto, a permanência do Brasil como o primeiro da lista, mesmo com a alteração na titularidade do poder executivo, e a elevação do Chile ao status de parceiro político relevante na região, ao lado do México e da Colômbia.

A análise dos discursos e comunicados oficiais do governo argentino revela algumas características do governo Macri em termos de política externa. Declaradamente opositor do regime chavista, o país manteve uma linha de ação ativa e crítica em relação ao governo Maduro, favorável às iniciativas da oposição, ao mesmo tempo em que buscou uma aproximação com Estados Unidos e Europa. A busca por apoio nas pautas regionais, sobretudo à aplicação da cláusula democrática do Mercosul, foi um dos objetivos principais da diplomacia argentina e um diferencial na política externa de Macri.

\section{Considerações finais}

Mesmo antes de assumir a presidência, Maurício Macri já apresentava os princípios norteadores de sua política externa: abertura ao mercado internacional, captação de investimentos estrangeiros, recuperação da credibilidade e confiança; retomada das relações com Reino Unido, Europa e Estados Unidos, cooperação, combate ao terrorismo e ao narcotráfico, segurança internacional e redução da pobreza.

Essas diretrizes alinharam-se ao discurso liberal em prol dos direitos humanos e das instituições democráticas. Porém, para alcançar seus objetivos e firmar protagonismo na América Latina, o governo argentino teve de enfrentar o acirramento da crise venezuelana. A relação amistosa, pragmática e estável, cultivada durante os governos de Kirchner e Chávez, que rendeu a incorporação da Venezuela ao Mercosul, experimentou um revés durante os dois primeiros anos da gestão Macri. Nesse ponto, o desempenho da diplomacia argentina indica alguns traços importantes da política externa macrista.

Em primeiro lugar, a necessidade de se afirmar internacionalmente como um governo oposto ao legado Kirchner com base numa reorientação da atuação diplomática. Nesse sentido destacam-se as recorrentes visitas de chefes de estado Europeus e as duas visitas de presidentes estadunidenses, Barack Obama e Donald Trump. Ao mesmo tempo a agenda bilateral Argentina-Venezuela foi substituída pelo isolamento regional. Instâncias como a UNASUL e a CELAC perderam espaço para a OEA - que se concretizou como um ambiente de denúncia e reafirmação do papel internacional do novo governo.

Em consonância com a proposta de política externa, o discurso entoado pelo presidente Macri e por seus chanceleres, Susana Malcorra e Jorge Faurie, se baseou em quatro eixos fundamentais: a opção pelo diálogo e a conciliação entre governo e oposição venezuelana, a defesa da democracia e dos direitos humanos, a não-ingerência, e a pauta econômica e comercial. A preocupação com a Venezuela, mais do que o cumprimento dos princípios democráticos foi a instabilidade que a crise poderia provocar no Mercosul - afetando as pretensões argentinas no bloco e consequentemente o acordo com a União Europeia.

Por esse motivo, posicionar-se contra o governo venezuelano, exercer pressão internacional e angariar apoio regional para suspensão da Venezuela no Mercosul foram prioridade para os diplomatas argentinos, sobretudo no momento em que o país exerceu presidência temporária do bloco. Como podemos ver, o Mercosul continuou a ser um mecanismo de integração importante. No entanto, a dimensão social, política e cultural, mais evidente durante os anos Kirchner, foi colocada em segundo plano pelo governo Macri, que optou por promover uma agenda comercial e econômica. A retomada dessa visão, semelhante aos parâmetros de política externa desenvolvidos nos anos 1980 e 1990, dialoga com objetivo de concretização do acordo 


\section{NEIBA}

VOLUME VII

Dossiê: SimpoRI 2018

\section{8}

comercial Mercosul-União Europeia e de aproximação com a Aliança do Pacífico.

O visível "amadurecimento" das relações com os Estados Unidos consolidado na visita do Secretário estadunidense John Kerry, em agosto de 2016, garantiu ao governo argentino o "reconhecimento" estadunidense - em evidente contraposição à relação entre os países durante os anos Kirchner. De acordo com Kerry, "o presidente Macri e a chanceler Malcorra estão empenhados em manter um relacionamento sólido e próximo com os Estados Unidos, assim como temos com a Argentina, que é extremamente importante neste momento." (KERRY, 2016 - tradução da autora)

O Brasil continuou a ser um parceiro estratégico, devido a importância do mercado brasileiro nas exportações argentinas. As relações com o vizinho brasileiro se mantiveram estáveis, mesmo com processo de impeachment da presidenta Dilma Rousseff. Entre janeiro de 2016 e dezembro de 2017 foram emitidos apenas quatro comunicados sobre o caso. Ao contrário do discurso adotado em relação à Venezuela a diplomacia argentina não manifestou opiniões críticas sobre o Brasil. Após a conclusão do processo que destituiu Dilma Rousseff, o governo argentino declarou respeito ao "processo institucional" retificando a vontade de "continuar o caminho da integração real e efetiva no marco do absoluto respeito pelos direitos humanos, instituições democráticas e direito internacional" (MREYC, 2016c - tradução da autora). A postura argentina em relação ao caso brasileiro foi modesta. O mais importante foi manter uma relação com o governo brasileiro, independente das questões internas. No mais, o substituto de Dilma Rousseff, Michel Temer, se apresentou como um aliado importante no caso venezuelano com apoio às pretensões argentinas.

A análise dos pronunciamentos e documentos oficiais realizadas por este trabalho traduz uma leitura dos fatos em um contexto específico. Ela não encerra a discussão do tema, mas abre novas perspectivas para estudos e pesquisas no campo da Política Externa Argentina. As contribuições dadas por este ensaio podem gerar entendimentos sobre a nova dinâmica social, econômica e política da América Latina. 


\section{NEIBA}

VOLUME VII

Dossiê: SimpoRI 2018

2018

\section{BIBLIOGRAFIA}

ARGENTINA (2016). Argentina en el mundo. Boletín de Cancilleria, Ministerio de Relaciones Exteriores y Culto, Buenos Aires, junho. Disponível em https://cancilleria.gob.ar/es/actualidad/boletin/argentina-en-el-mundo Acesso em 20 de junho de 2018.

CARMO, M (2016). Macri tenta 'guinada' em política externa argentina e analistas esperam avanços com Brasil. BBC, Buenos Aires. 28 de fevereiro de 2016. Disponível em http://www.bbc.com/portuguese/noticias/2016/02/160225_macri_politica_externa_mc_pai Acesso em 25 out 2017

CARLIN, J (2016). A chanceler argentina Susana Malcorra: pragmática e sonhadora. El País, Londres. 15 de maio de 2016. Disponível em < https://brasil.elpais.com/brasil/2016/05/14/internacional/1463244838_230706.html>Acesso em 6 de novembro de 2017.

COELHO, A.L \& SANTOS, V.S (2014). A análise da política externa do governo Dilma Rousseff na perspectiva dos pronunciamentos oficiais na ONU. Mural Internacional, v.5, n.2, Jul-Dez.

CUÉ, C.E (2017). Pablo Avelluto: "Maurício Macri marca o final de uma era". El País, Buenos Aires. 30 de outubro de 2017. Disponível em https://brasil.elpais.com/brasil/2017/10/30/internacional/1509324437_192512.html Acesso em 10 de novembro de 2017.

FAIRCLOUGH, Norman. 2001. [1992]. Discurso e Mudança Social. Brasília: Editora UnB

FAURIE, J (2017). Faurie: "Estamos ante una crisis que tiene una dimensión humanitaria". Ministerio de Relaciones Exteriores y Culto, junho, Buenos Aires. Disponível em < https://cancilleria.gob.ar/es/actualidad/comunicados/faurie-estamos-ante-una-crisis-que-tieneuna-dimension-humanitaria> Acesso em 29 de junho de 2018.

FLORES, F. I. P. (2007). Ideologia e política externa do Brasil e do México frente às opções de integração regional (199o - 2006) / Fidel Irving Pérez Flores - Rio de Janeiro: UFRJ/IFCS.

HORTA, L.F.C.B.R (2012). O conceito de diplomacia presidencial. $1^{\circ}$ Seminário Nacional de Pós-Graduação em Relações Internacionais. Brasília, DF, jul.

KRESS, G (1990). Critical Discourse Analysis. In: W. G. (org.). Annual Review of Applied Linguistics 11. p. 84-99, 1990.

MACRI, M (2015). Palabras del Presidente Mauricio Macri en la Cumbre Del Mercosur en Asunción, Republica Del Paraguay. Buenos Aires, Casa Rosada, dezembro. Disponível em < https://www.casarosada.gob.ar/informacion/discursos/35112-palabras-del-presidenteen-la-cumbre-del-mercosur-en-paraguay> Acesso em 22 de junho de 2018.

(2015). Discurso del Presidente de la Nación, Mauricio Macri, en la 71a. Asamblea General de las Naciones Unidas. Buenos Aires, Ministerio de Relaciones Exteriores y Culto, setembro. Disponível em < https://cancilleria.gob.ar/es/actualidad/comunicados/discurso-del-presidente-de-la-nacion-mauricio-macri-en-la-71a-asamblea> Acesso em 28 de junho de 2018. 


\section{NEIBA}

(2017). Exposisión del Presidente de la Nación, Mauricio Macri, en el $51^{a}$ Cumbre Del Mercosur Y Países Asociados. Buenos

Aires, Casa Rosada, dezembro. Disponível em < https://www.casarosada.gob.ar/informacion/discursos/41525-el-presidente-macrihablo-en-la-51-cumbre-del-mercosur> Acesso em 2 de junho de 2018.

MALCORRA, S (2016). Malcorra sobre la visita de Obama: "La Argentina está reinsertándose en el mundo". Buenos Aires, Ministerio de Relaciones Exteriores y Culto, fevereiro. Disponível em <https://cancilleria.gob.ar/es/actualidad/comunicados/malcorra-sobre-la-visitade-obama-la-argentina-esta-reinsertandose-en-el> Acesso em o1 de julho de 2018

(2016A) Declaraciones de la canciller Malcorra. Buenos Aires, Ministerio de Relaciones Exteriores y Culto, maio.

Disponível em < https://cancilleria.gob.ar/es/actualidad/comunicados/declaraciones-de-la-canciller-malcorra> Acesso em o1 de julho de 2018

(2016B). Declaraciones de la Canciller Susana Malcorra. Buenos Aires, Ministerio de Relaciones Exteriores y Culto, maio. Disponível em < https://cancilleria.gob.ar/es/actualidad/comunicados/declaraciones-de-la-canciller-susana-malcorra> Acesso em o1 de julho de 2018

(2016C). Malcorra: "La situación en Venezuela es muy delicada". Buenos Aires, Ministerio de Relaciones Exteriores y Culto, maio. Disponível em < https://cancilleria.gob.ar/es/actualidad/comunicados/malcorra-la-situacion-en-venezuela-es-muydelicada> Acesso em o1 de julho de 2018

(2016D). Malcorra se reunió con el presidente Temer en Brasil. Buenos Aires, Ministerio de Relaciones Exteriores y Culto, dezembro. Disponível em < https://cancilleria.gob.ar/es/actualidad/comunicados/malcorra-se-reunio-con-el-presidente-temer-enbrasil> Acesso em o3 de julho de 2018

(2017). Declaraciones de la Canciller Malcorra sobre la situación institucional en Venezuela. Buenos Aires, Ministerio de Relaciones Exteriores y Culto, abril. Disponível em < https://cancilleria.gob.ar/es/actualidad/comunicados/declaraciones-de-lacanciller-malcorra-sobre-la-situacion-institucional-en> Acesso em o3 de julho de 2018

(2017A). Discurso de la Canciller argentina, Susana Malcorra, en ocasión de la sesión extraordinaria del Consejo Permanente de la OEA del 3 de abril de 2017, donde se consideró la situación en Venezuela. Ministerio de Relaciones Exteriores y Culto, abril. Disponível em < https://cancilleria.gob.ar/es/actualidad/discursos/venezuela-debe-asegurar-la-separacion-de-poderes-el-estadode-derecho-los>Acesso em o3 de julho de 2018

MELO, Iran F (2009) Análise do Discurso e Análise Crítica do Discurso: desdobramentos e intersecções. Letra Magna, ano, n.11.

MICHETTI, G (2017) Discurso de la Vicepresidente de la Nación, Sra. Gabriela Michetti, en la $72 a$. Asamblea General de las Naciones Unidas. Buenos Aires, Ministerio de Relaciones Exteriores y Culto, setembro. Disponível em < http://enaun.mrecic.gov.ar/es/discurso-dela-vicepresidente-de-la-naci\%C3\%B3n-sra-gabriela-michetti-en-la-72a-asamblea-general-de-las> Acesso em o5 de julho de 2018

MINISTERIO DE RELACIONES EXTERIORES Y CULTO (2016). Asunción de los nuevos integrantes de la Asamblea Nacional de Venezuela. Buenos Aires, Ministerio de Releciones Exteriores y Culto. Disponível em https://cancilleria.gob.ar/es/actualidad/comunicados/asuncion-de-los-nuevos-integrantes-de-la-asamblea-nacional-de-venezuela Acesso em 23 de junho de 2018. 


\section{NEIBA}

(2016A). Comunicado sobre el referendo venezolano. Buenos Aires, Ministerio de Relaciones Exteriores y Culto. Disponível em < https://cancilleria.gob.ar/es/actualidad/comunicados/comunicado-sobre-el-referendo-venezolano>Acesso em 23 de junho de 2018.

(2016B). Venezuela: Llamado al diálogo entre el Gobierno y la oposición. Buenos Aires, Ministerio de Relaciones Exteriores y Culto. Disponível em < https://cancilleria.gob.ar/es/actualidad/comunicados/venezuela-llamado-al-dialogo-entre-elgobierno-y-la-oposicion> Acesso em 23 de junho de 2018.

(2016C). Proceso institucional en Brasil. Buenos Aires, Ministerio de Relaciones Exteriores y Culto. Disponível em < https://cancilleria.gob.ar/es/actualidad/comunicados/proceso-institucional-en-brasil> Acesso em 24 de junho de 2018.

(2016D). Liberación de opositores en Venezuela. Buenos Aires, Ministerio de Relaciones Exteriores y Culto. Disponível em < https://cancilleria.gob.ar/es/actualidad/comunicados/liberacion-de-opositores-en-venezuela> Acesso em 24 de junho de 2018.

(2017). Declaración Conjunta sobre la situación en Venezuela. Buenos Aires, Ministerio de Relaciones Exteriores y Culto. Disponível em < https://cancilleria.gob.ar/es/actualidad/comunicados/declaracion-conjunta-sobre-la-situacion-en-venezuela> Acesso em 24 de junho de 2018.

NOGUEIRA, C (2001). A análise do discurso. Em L. Almeida e E. Fernandes (Edts), Métodos e técnicas de avaliação: novos contributos para a prática e investigação. Braga: CEEP.

PANIZZA, F. (2006). La marea rosa. Análise de Conjuntura OPSA, Rio de Janeiro, n. 8, p. 1-16, ago. Disponível em: http://www.opsa.com.br/images/pdf/analise/21_analises_La_marea_rosa.pdf.Acesso em: 16 de junho de 2018

PEREIRA, Matheus O (2016). A vitória de Maurício Macri e as Relações Internacionais Sul-Americanas: mudança de época? IN: AYERBE, Luis F (Org). Análise de conjuntura em relações internacionais [recurso eletrônico]: abordagens e processos. 1. ed. - São Paulo : Cultura Acadêmica. Disponível em

https://s3.amazonaws.com/academia.edu.documents/47544312/Livro_Analise_de_conjuntura_em_Relacoes_Internacionais.pdf?AWS AccessKeyld=AKIAIWOWYYGZ2Y53UL3A\&Expires $=1532535135$ \&Signature $=7$ Emergl8fCGcAVQgLdxW8fWLxyA\%3D\&responsecontent-disposition=inline $\% 3 B \% 20$ filename\%3DAnalise_de_conjuntura_em_Relacoes_Intern.pdf\#page=132 Acesso em 10 de jun de 2018.

PRETO, Adriana F (2006). O Conceito de Diplomacia Presidencial: o papel da Presidência da República na formulação de política externa. Dissertação de Mestrado, Programa de Pós-Graduação em Ciência Política, USP, São Paulo.

RUIZ, José B (2010). Venezuela y Argentina en la era Chávez y Kirchner: ?coincidencia ideologica o pragmatismo?. IN: La política exterior del gobierno de Cristina Fernández: apreciaciones promediando su mandato. 1a ed. Rosario: UNR Editora. Editorial de la Universidad Nacional de Rosario, v. 5, 490 p.

SCHENONI, Luis L (2016). La Política Exterior después de los Kirchner. Revista Iberoamericana, XVI, 61 (2016), p. 247-252

SIMONOFF, A (2016). O "novo" e o "velho" na política externa argentina do governo Cambiemos. International Centre for Trade and Sustainable Development. 10 de maio de 2016. Disponível em < https://www.ictsd.org/bridges-news/pontes/news/o-

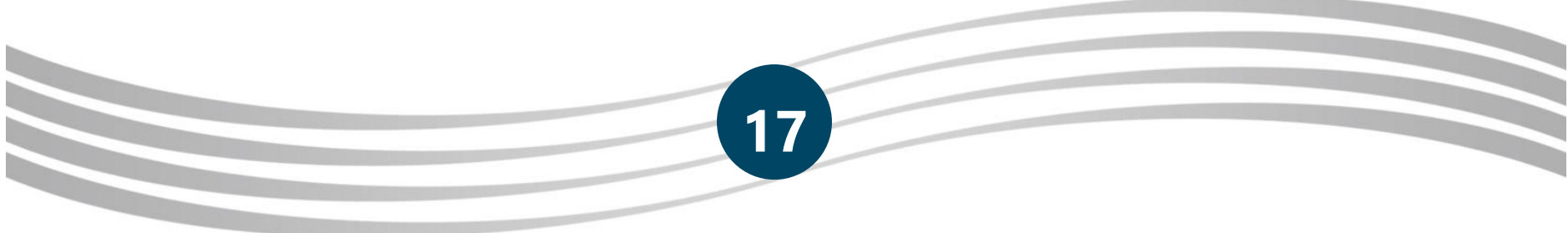




\section{NEIBA}

VOLUME VII

Dossiê: SimpoRI 2018

\section{8}

$\% E_{2} \% 80 \% 9$ Cnovo\% $\% 2 \% 80 \% g D-e-0-\% E_{2} \% 80 \% g$ Cvelho\%E2\%80\%gD-na-12pol\%C3\%ADtica-externa-argentina-do-governo-decambiemos> Acesso em 14 outubro de 2017.

VAN DIJK, T. A. (1993). Principles of Critical Discourse Analysis. Discourse \& Society, 4(2), 249-283. Disponível em <https://doi.org/10.1177/0957926593004002006> Acesso em 10 de fevereiro de 2019.

; MEDEIROS, B. W.; ANDRADE, M. L (2013). Análise crítica do discurso multidisciplinar: um apelo em favor da diversidade. Linha D'Água, v. 26, n. 2, p. 351-381, 16 dez. Disponível em < http://www.revistas.usp.br/linhadagua/article/view/65164> Acesso em 10 de fevereiro de 2019.

ZELICOVICH, J (2016). Barajar y dar de nuevo: ¿Cuál es la estrategia de inserción internacional de la política comercial externa de la gestión Macri en sus primeros 6 meses de gobierno?. XII Congreso Nacional y V Congresso Internacional sobre Democracia. Facultad de Ciencia Politica y Relaciones Internacionales. Universidad Nacional de Rosario. Rosario. 